\title{
Décès de M. Léopold Boissier, membre et ancien président du CICR
}

Le Comité international a été douloureusement frappé par le décès, survenu accidentellement le 22 octobre 1968, de son ancien président, M. Léopold Boissier. Il gardera de lui, avec une fidèle reconnaissance, le souvenir d'un homme qui a voué le meilleur de ses forces, tant intellectuelles que morales, au service de la Croix-Rouge.

Lors des obsèques, les autorités genevoises, cantonales et municipales, le corps diplomatique, les organisations internationales et l'Université étaient représențés par leurs personnalités dirigeantes. Etaient présents les Présidents des Sociétés de la Croix-Rouge de l'Allemagne fédérale et de Suisse, de même que les représentants des Croix-Rouges nationales de plusieurs pays, le Secrétaire général de la Ligue ainsi que de nombreux membres et collaborateurs du CICR. Ce fut M. Gonard, président du CICR, qui rappela tout ce que l'œuvre de la Croix-Rouge doit au disparu. Il rendit hommage à sa mémoire dans les termes suivants:

Tout, dans la carrière de notre collègue disparu, semblait le destiner à servir la Croix-Rouge et plus particulièrement ce Comité international, qui en fut le fondateur.

Il était issu d'une ancienne famille genevoise dans laquelle le dévouement au prochain était comme une seconde nature et qui a laissé, notamment sous la forme d'une fondation, des traces durables de sa sollicitude envers les déshérités. Et l'on sait que $M^{m e}$ de Gasparin, née Boissier, a aidé Henry Dunant lui-même dans ses débuts difficiles. Non moins traditionnel $y$ était le silence gardé sur le bien accompli, vertu évangélique bien rare aujourd'hui, et qui donnait au geste un prix particulier. C'est à cette noble école que l'avait élevé son père, Edmond Boissier, qui avait été sa vie durant, membre du Comité international de la Croix-Rouge, puis vice-président, 
et qui, le premier, en 1920, avait ébauché les principes de la Croix-Rouge, aujourd'hui proclamés universellement.

Les différentes étapes de la vie si féconde de Léopold Boissier ont fortement contribué à former ce que je me permettrai d'appeler sa "personnalité Croix-Rouge ». Docteur en droit, professeur de droit constitutionnel comparé à l'Université de Genève, on retrouvera les qualités du juriste et du savant dans celui qui, avant même d'être Président, dirigea la Commission juridique du CICR, ainsi qu'un groupe de travail chargé de définir ses principes d'action et son programme.

Depuis lors, placé à la tête du CICR, il se montrera le gardien attentif de la doctrine, veillant à maintenir l'institution sur la voie toute droite que ses fondateurs lui avaient tracée, car il savait que de cette rectitude elle tire sa vigueur et son crédit.

Le diplomate ensuite, qui prit son essor sous l'égide des Gustave Ador et des Max Huber, au service de la Confédération suisse, on le retrouve dans l'homme qui présida aux destinées du CICR, dont l'action, purement internationale, implique des relations étroites avec les représentants de tous les pays. C'est là que Léopold Boissier, avec cette courtoisie profonde qu'on lui connaissait, s'employa, avec un rare bonheur, à aplanir les difficultés, à éviter des querelles et finalement à établir avec les sociétés et les dirigeants des divers pays des liens de confiance et une coopération effective. Car il avait compris que l'avenir de la Croix-Rouge et son salut résidaient dans son union et son universalité.

La troisième facette de son individualité reflète son activité comme Secrétaire général de l'Union interparlementaire et comme président d'associations cuvrant pour la paix, alors qu'il plaidait sans relâche pour la promotion des droits humains, le respect des minorités et pour l'avènement d'un monde plus juste, d'où l'oppression serait bannie. Elle l'a conduit finalement, au sein de la Croix-Rouge, à agir en faveur d'une meilleure entente entre les peuples et pour le développement de l'esprit de paix. Nous n'oublions pas que c'est sous sa présidence que le CICR fut sollicité de jouer, lors de la crise de Cuba, alors que la paix mondiale parut un instant menacée, un rôle d'arbitre. C'est à Léopold Boissier que revient le mérite d'avoir compris que, dans une heure aussi grave, le CICR ne pouvait se dérober sans faillir à sa mission.

L'auvre d'un président se distingue difficilement de l'auvre d'une institution. Je voudrais relever cependant quelques domaines dans lesquels il a apporté une contribution très personnelle et qu'il a marqués de son empreinte. Membre du Comité international de la Croix-Rouge depuis 1946, il en fut 
nommé président en septembre 1955. Dès l'année suivante, il eut la lourde responsabilité de diriger l'action du CICR lors des événements de Hongrie et de Suez. Il se rendit lui-même à Budapest en février 1957 et, au mois de novembre de la même année, conduisit la délégation du CICR à la $X I X^{e}$ Conférence internationale de la Croix-Rouge, à la Nouvelle-Delhi, où il présida le Conseil des Délégués.

Sous son inspiration, le CICR a eu à affronter des tâches toujours plus vastes, alors que se multipliaient les conflits entre les hommes, toujours plus délicates aussi, s'agissant non plus tant de guerres internationales de type classique que de ces états de troubles intérieurs, de ces "guerres qui n'osent pas dire leur nom ", selon sa propre expression. Les événements ne l'ont pas pris au dépourvu et l'attribution, en 1963, du Prix Nobel, obtenu par le CICR conjointement avec la Ligue des Sociétés de la Croix-Rouge, notre institution scur, marque véritablement le couronnement de sa carrière.

La même année, notre collègue eut le privilège - et combien l'avait-il mérité - de présider le Congrès du Centenaire de la Croix-Rouge et de participer aux cérémonies qui marquèrent le premier siècle d'existence de cette institution, née dans cette cité qu'il n'a cessé d'honorer tout au long d'une vie faite d'intégrité morale et de désintéressement, au service de l'humanité.

Lorsqu'en 1964 Boissier résigna ses fonctions présidentielles, il reçut l'émouvant témoignage des délégués de nombreuses Sociétés nationales de la Croix-Rouge réunis à Genève.

Mais en quittant la présidence, notre collègue regretté ne mit nullement fin à son activité. Il demeura membre du Comité, de notre Conseil de Présidence, de notre Commission juridique, où son expérience, ses avis faisaient autorité. Il avait même assumé une nouvelle entreprise, en participant à la fondation et à l'inspiration de l'Institut Henry-Dunant, sorte d'Université de la Croix-Rouge, encore en devenir, mais déjà riche de promesses.

La mort nous l'a ôté en pleine force, prêt à se dévouer, encore et sans compter, pour alléger la souffrance humaine, chaque fois que, pour une noble cause, on aurait fait appel à son sens inné de la justice et d'un idéal fraternel. Mes collègues et moi-même, nous garderons toujourș la mémoire de cet homme droit et courageux, qui a bien mérité de l'humanité et qui demeurera longtemps en exemple aux générations qui auront le redoutable honneur de le suivre et de continuer son auvre. 